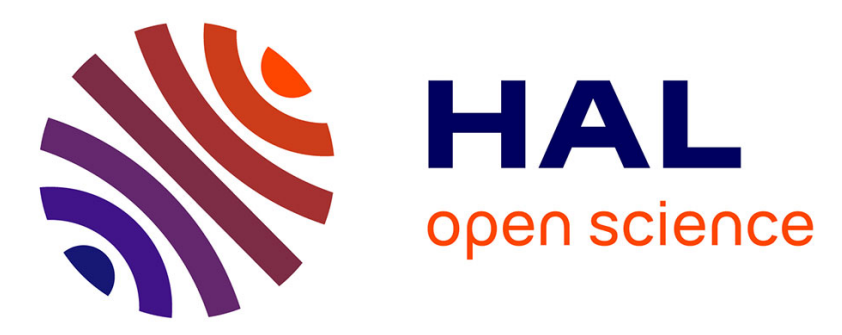

\title{
Charpy V-Notch Impact Testing and Brittle Fracture in an A508 CL.3 Bainitic Steel
}

\author{
Mohamed Tahar, C. Brillaud, Pierre Forget, Roland Piques
}

\section{To cite this version:}

Mohamed Tahar, C. Brillaud, Pierre Forget, Roland Piques. Charpy V-Notch Impact Testing and Brittle Fracture in an A508 CL.3 Bainitic Steel. Journal de Physique IV Proceedings, 1997, 07 (C3), pp.C3-873-C3-878. 10.1051/jp4:19973147 . jpa-00255435

\section{HAL Id: jpa-00255435 https://hal.science/jpa-00255435}

Submitted on 1 Jan 1997

HAL is a multi-disciplinary open access archive for the deposit and dissemination of scientific research documents, whether they are published or not. The documents may come from teaching and research institutions in France or abroad, or from public or private research centers.
L'archive ouverte pluridisciplinaire HAL, est destinée au dépôt et à la diffusion de documents scientifiques de niveau recherche, publiés ou non, émanant des établissements d'enseignement et de recherche français ou étrangers, des laboratoires publics ou privés. 
J. PHYS IV FRANC'E 7 (1997)

Colloque C3, Supplément au Journal de Physique III d'août 1997

\title{
Charpy V-Notch Impact Testing and Brittle Fracture in an A508 CL.3 Bainitic Steel
}

\author{
M. Tahar, C. Brillaud*, P. Forget** and R. Piques \\ École des Mines de Paris, Centre des Matériaux, URA No866 du CNRS, B.P. 87, 91003 Evry cedex, \\ France \\ *EDF-GDL-SCMI, B.P. 23, 37420 Avoine, France \\ ** Commissariat à l'Énergie Atomique (SRMA), 91191 Gif-sur-Yvette, France
}

\begin{abstract}
Résumé. Les essais charpy sont largement utilisés pour prévoir la ténacité de pièces forgées comme par exemple les viroles des cuves nucléaires des réacteurs à eau sous pression REP. Dans les aciers bainitiques de type A508 $\mathrm{Cl} 3$ testés à basse température, il se produit une rupture instable par clivage. Les résulats d'un programme expérimental et de simulations numériques sont présentés ici dans le but d'établir une relation non empirique entre résilience $\mathrm{KCV}$ et ténacité $\mathrm{K}_{I C}$. Dans ce papier, le modèle de Beremin qui est basé sur un concept de contrainte critique et sur une statistique de type Weibull est appliqué aux seuls essais Charpy.
\end{abstract}

\begin{abstract}
Charpy V-notch impact testing is widely used in the toughness diagnostic of large forged components, e.g. the vessel of pressurized water reactors (PWR). In an A508 Cl.3 bainitic steel tested at low temperature, cleavage occurs at the initiation of unstable failure. The results reported here are part of both an experimental program and numerical investigations in order to establish a non-empirical relationship between Charpy V-notch energy CVN and fracture toughness $\mathrm{K}_{I C}$. The Beremin model which is based on a critical fracture stress concept and Weibull statistics, is only applied on CVN tests.
\end{abstract}

\section{INTRODUCTION}

The Charpy V-notch impact test is often used as a simplified method to determine an intrinsic $K_{I C}$. It requires small specimens $\left(10^{*} 10^{*} 55 \mathrm{~mm}^{3}\right.$ with a $2 \mathrm{~mm}$ deep notch), but it is not clear if the cleavage strength at low temperature is independent of dynamic effects (oscillations, high strain rates, local temperature rises etc.). The present work is part of a more extensive experimental and numerical investigation. An objective of this program is the determination of a better relationship between CVN and $\mathrm{K}_{I C}$ on the lower shelf for an A508 Cl.3 bainitic nuclear pressure vessel steel (see the chemical composition in table 1), by using the Beremin model [1].

Table 1 : Chemical composition in weight per cent

\begin{tabular}{|c|c|c|c|c|c|c|c|c|c|c|}
\hline $\mathrm{C}$ & $\mathrm{S}$ & $\mathrm{P}$ & $\mathrm{Si}$ & $\mathrm{Mn}$ & $\mathrm{Ni}$ & $\mathrm{Cr}$ & $\mathrm{Mo}$ & $\mathrm{Cu}$ & $\mathrm{Co}$ & $\mathrm{V}$ \\
\hline 0,16 & 0,004 & 0,008 & 0,22 & $\mathrm{1}, 33$ & 0,76 & 0,22 & 0,51 & 0,07 & 0,017 & $\leq 0,01$ \\
\hline
\end{tabular}

This model is based on the existence of a temperature-independent critical cleavage stress. Plastic deformation induces the nucleation of micro-cracks which are generally oriented normal to the direction of the maximum principal stress $\sigma_{1}$. Instability occurs when $\sigma_{1}$ reaches a critical stress in a representative volume $V_{o}$ (the weakest link theory can be applied). Using a power law distribution for the size of the micro-cracks, the Beremin criterion can be expressed in the following statistical form :

$$
P_{r}=1-\exp -\left(\frac{\sigma_{w}}{\sigma_{u}}\right)^{m} \text { with } \sigma_{w}=\sqrt[m]{\int_{V_{p}} \sigma_{1}^{m} \frac{d v}{V_{o}}}
$$

where $P_{r}$ is the cumulative failure probability, and $\sigma_{w}$ the Weibull stress (summation function of $\sigma_{1}$ on the plastically deformed volume $V_{p}$ ). $V_{0}$ is a rlaracteristic volume of the material containing several grains. Here, $l_{0}=(50 \mu \mathrm{m})^{3}$. $\sigma_{u}$ is closely linked to the intrinsic cleavage stress and $m$ is the 
Weibull exponent which describes the scatter in the flaw distribution. Two parameters are required : $m$ and $V_{o} \sigma_{u}^{m}$.

Normalised Charpy V-notch specimens were tested at low temperature on an instrumented standard pendulum impact machine. The uniaxial flow properties have been investigated under both static and dynamic loading conditions.

Different simulations of the impact tests are discussed using 2-D plane strain Finite Element Method (FEM) analyses in order to identify the more realistic hypothesis. Therefore it is possible to optimize the calculations of the cumulative failure probabilities $P_{r}$ in Charpy V-notch specimens for comparing with cracked CT specimen ones.

\section{MATERIAL AND UNIAXIAL PROPERTIES}

The tempered bainitic material is a representative sample of the inner part of a pressure vessel wall with an average grain size of about $20 \mu \mathrm{m}$. The orientations of the smooth and Charpy V-notch specimens are respectively $\mathrm{T}$ and $\mathrm{T}-\mathrm{L}$. The material just below the notch root of the Charpy specimen undergoes high strain-rate deformation during the tests. Thus, the uniaxial flow properties have been investigated under both static and dynamic loading conditions in a wide range of temperature from. $196^{\circ} \mathrm{C}$ up to $+100^{\circ} \mathrm{C}$. Young's modulus, Poisson's ratio and the isotropic strain hardening parameter are considered strain-rate independent.

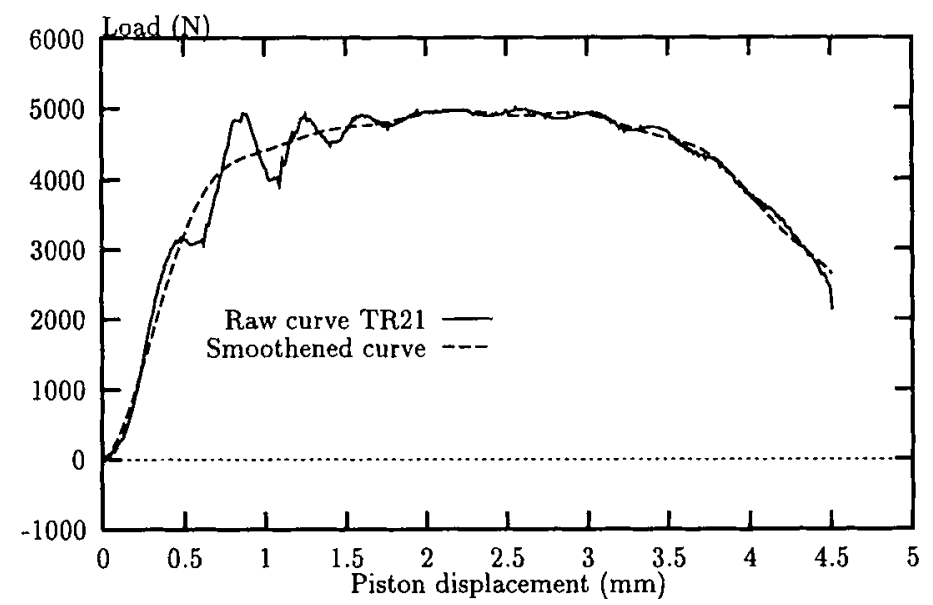

Figure 1: Raw force-displacement curve obtained from a dynamic test at $-10^{\circ} \mathrm{C}$ and curve corrected by a numerical smoothing.

Figure 1 shows a raw uniaxial load vs. displacement curve and the plot of the corresponding result smoothened by FFT (Fast Fourier Transform) in order to calculate the yield stress $\sigma_{y}$. The piston is equipped with a small rubber pad. The determination of the yield stress $\sigma_{y}$ was carried out in tension at $\dot{\varepsilon} \simeq 10^{-4} \mathrm{~s}^{-1}$ and $\dot{\varepsilon} \simeq 50 \mathrm{~s}^{-1}$. A shifting procedure [2-3] enables the definition of a modified temperature parameter $\mathrm{T}^{*}$ as :

$$
T^{*}=T \ln \left(\frac{\dot{\varepsilon_{o}}}{\dot{\varepsilon}}\right)
$$

where $T$ denotes the temperature in Kelvin and $\dot{\varepsilon_{0}}$ equals $10^{8}$.

The influence of high strain rate has already been studied in similar materials. The work of Pluvinage and Marandet [4] deals with both tensile and compressive tests whereas Henry et al. [5] present dynamic yield stress results for tension only. These results have been reported in figure 2 together with our own results. This figure shows that yield stress values obtained by tensile testing lie just below results obtained by averaging tensile and compressive data (Pluvinage $[4]$. The difference could be related to the strength differential effect [6] which explains the higher yel: strength measured in compression. 
Benett and Sinclair [2] and Ritchie et al. [3] suggest a power law correlation between the yield stress $\sigma_{y}(\mathrm{MPa})$ and the modified temperature parameter $\mathrm{T}^{*}$ :

$$
\sigma_{y}=C\left(T^{*}\right)^{d}
$$

Values of the parameters $\mathrm{C}$ and $\mathrm{d}$ obtained by different authors are reported just below :

Pluvinage and Marandet [4] (tension and compression) $\mathrm{C}=75866 \mathrm{~d}=-0.573$

Henry et al. [5] (tension) $\quad C=35188 \mathrm{~d}=-0.487$

Present study (tension) $\quad C=105229 \mathrm{~d}=-0.618$

The values obtained in our study were used to fit the parameters of the elastic-viscoplastic law implemented in the finite element code used for the numerical computations (see 4.1).

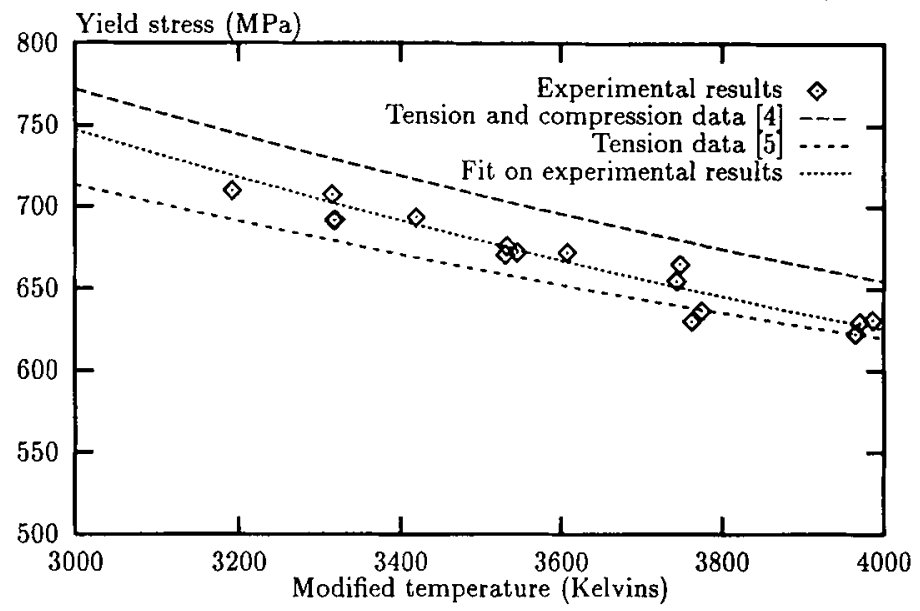

Figure 2: Evolution of yield stress with the modified temperature

\section{CHARPY V-NOTCH: EXPERIMENTAL PROCEDURE AND RESULTS}

Charpy V-notch tests with a nominal impact velocity of $5 \mathrm{~m} / \mathrm{s}$ were carried out on a standard pendulum impact machine of 350 Joules capacity. The instrumented striker allows to record the evolution of load vs. time.

For cleavage $\left[-120^{\circ} \mathrm{C} \leq T \leq-80^{\circ} \mathrm{C}\right.$ ], the times to failure lie in the range 0.1 to $1 \mathrm{~ms}$. Figure 3 illustrates a typical load vs. displacement curve.

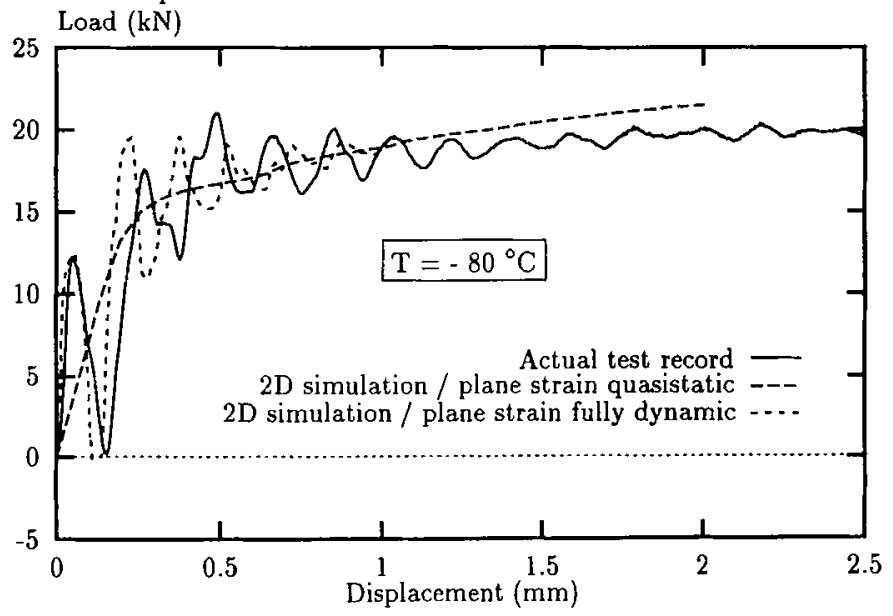

Figure 3 : Comparison of measured and computed load-displacement curves.

Since in most cases failure occurs after several oscillations, the influence of kinetic energy can be neglected as compared with the total energy [i]. This means that a quasistatic modelling procedure 
can be applied. Moreover, fracture surface observations showed no stable crack propagation at temperatures below $-80^{\circ} \mathrm{C}$. Therefore, a simple elastic-viscoplastic behaviour not accounting for ductile damage seems to be appropriate for the numerical simulation of the dynamic failure process. In figure 4, the evolution of Charpy V-notch energy with temperature is reported. Using $7 \mathrm{daJ} / \mathrm{cm}^{2}$ for the Charpy V-notch reference energy, the DBTT (ductile to brittle transition temperature) is $-60^{\circ} \mathrm{C}$

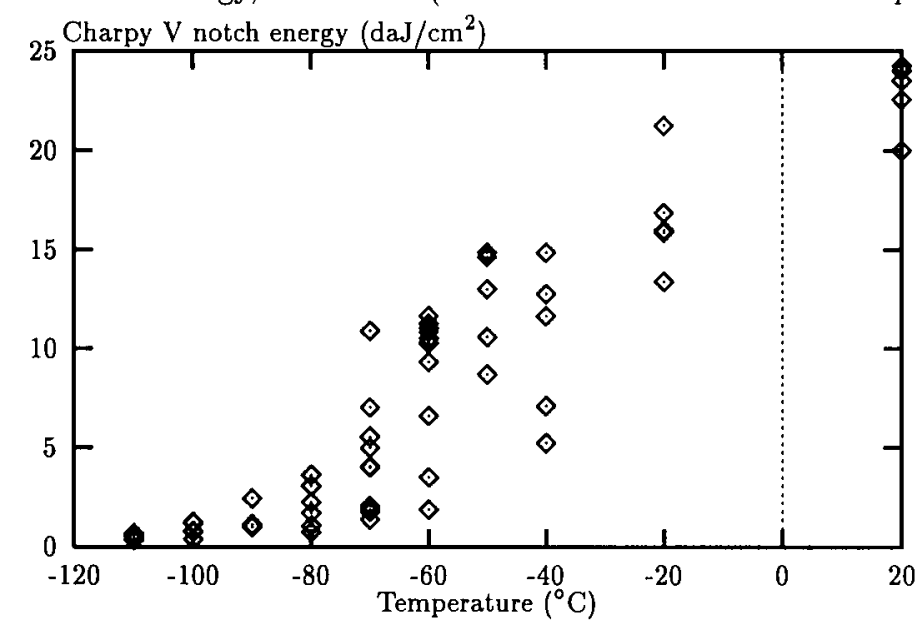

Figure 4: Charpy V notch energy vs. temperature.

\section{NUMERICAL COMPUTATIONS}

\subsection{Numerical procedures}

In 2-D, only one half of the specimen needs to be modelled. The mesh consists of 2300 four-noded quadratic isoparametric elements with reduced integration. The element size just below the notch root is in the order of $30 \mu \mathrm{m}$. Plane strain conditions have been assumed. The mesh is locally refined for modelling the surfaces in contact with the striker and the anvil (prescribed as rigid analytical contact surfaces), allowing a good description of sliding friction. For further details see Refs [7] and [8].

In order to use quasistatic as well as fully dynamic (including inertia terms) analyses, we chose the ABAQUS code (release 5.4). A large deformation formulation is used. As it has been underlined in 2 , the A508 steel can be considered as an elastic-viscoplastic material with isotropic hardening. The Cowper-Symonds formulation implemented in ABAQUS has been applied in order to incorporate strain-rate effects.

$$
\sigma=\sigma_{0}\left(1+\left(\frac{\dot{\varepsilon}_{e q}}{\dot{\varepsilon_{o}}}\right)^{1 / p}\right)
$$

with

$\sigma_{0}$ : static flow stress

$\dot{\varepsilon_{o}}:$ normalisation parameter $\varepsilon_{\text {eq }}$ : Von Mises equivalent plastic strain rate $\mathrm{p}$ : strain rate hardening exponent

\subsection{Results}

Figure 3 shows a comparison between the experimental data and the simulated load vs. displacement curves obtained by quasistatic and fully dynamic 2-D plane strain computations. For this test $(-80$ ${ }^{\circ} \mathrm{C}$ ), the modelling of the oscillation regime is in good agreement with the experimental data. For displacements exceeding $0.5 \mathrm{~mm}$, inertial oscillations are largely damped due to plasticity. This damping effect has been found to be much more pronounced for the maximum principal stresses just below the notch root (figure 5). Thus a quasistatic computing procedure (i.e. neglecting inertial terms) is considered a generally quite satisfactory approach to discuss instable fracture in this material at low temperature. More attention has to be paid to simulate tests at even lower temperature lew 
than $-120^{\circ} \mathrm{C}$ for example). For displacements exceeding $1 \mathrm{~mm}$, the 2-D plane strain simulation overestimates the experimental load-displacement curve. For the 3 - $\mathrm{D}$ model, a good agreement was found (see Ref 9). Evidently, a 3-D analysis is more suitable, but would be extremely costly. It has finally been judged unnecessary.

Recent investigations (Ref 9) concerning a comparison of isothermal and adiabatic conditions show that adiabatic heating is extremely confined at the notch root. Consequently, its influence on the peak tensile stress can be neglected.

\section{LOCAL APPROACH}

The experimental results are analysed in terms of the Beremin model [1], which is applied in a postprocessing routine. The iterative identification of the Weibull statistics parameters $m$ and $\sigma_{u}$ has been made using axisymmetric notched tensile bars tested at $-196^{\circ} \mathrm{C}$ and $-160^{\circ} \mathrm{C}$ under static strain rate conditions $\left(\simeq 10^{-4} s^{-1}\right)$. The finite element calculations of the Weibull stress $\sigma_{w}$ as a function of the stress and deformation fields by using Eq. (1) were realized by means of the Zebulon code which has been developed at Ecole des Mines de Paris. The details of bath experimental and numerical investigations are presented elsewhere [10]. The paramaters obtained by this procedure were found to be : $m=20 \sigma_{u}=3059 \mathrm{MPa}$

After the identification of the parameters $m$ and $\sigma_{u}$, the 2-D fully dynamic and viscoplastic quasistatic simulations were made in order to modelling the Charpy V-notch specimens. The Weibull stress $\sigma_{w}$ was computed in a post-processing routine. Due to spreading plasticity, it has been found a much more pronounced damping effect for the Weibull stresses just below the notch root (figure 5b): the 2-D fully dynamic and viscoplastic quasistatic calculations are in good agreement. Consequently a 2-D viscoplastic quasistatic model will be considered sufficiently accurate.
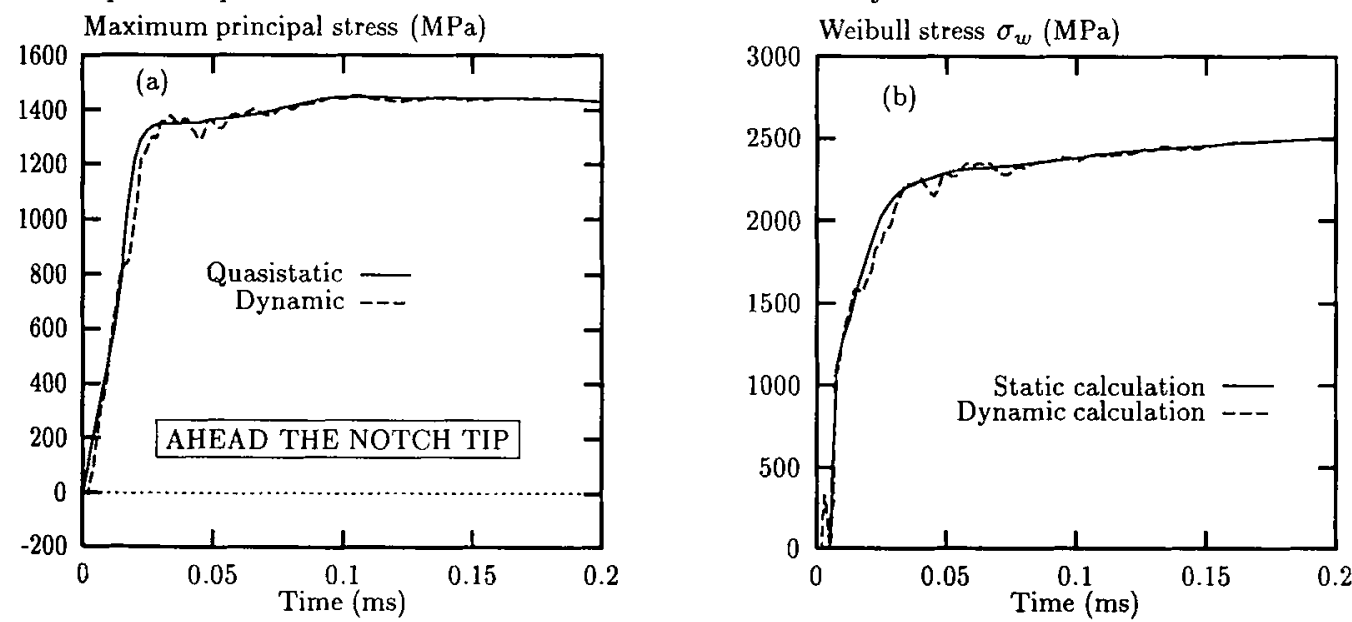

Figure 5 : (a) Evolution of the maximum principal stress ahead of the notch with deflection for a static analysis and a dynamic analysis. (b) Evolution of the Weibull stress with time for a static analysis and a dynamic analysis.

Additionnal work is needed to present key curves giving the cumulative failure probabilities $P_{r}$ in Charpy V-notch specimens for comparing for example with cracked CT specimens ones. A new relationship between Charpy V-notch Energy CVN and fracture toughness $\mathrm{K}_{I C}$ will be proposed on the basis of such a key curves. 


\section{CONCLUSIONS}

- A parameter combining strain rate and temperature enables the determination of the viscoplastic law parameters using smooth specimens tested at $\simeq 10^{-4} \mathrm{~s}^{-1}$ and $\simeq 50 \mathrm{~s}^{-1}$ in a wide range of temperature $\left[-196^{\circ} \mathrm{C},+100^{\circ} \mathrm{C}\right]$

- Due to spreading plasticity, it has been found a much more pronounced damping effect for the Weibull stresses just below the notch root of the Charpy specimens.

- 2-D plane strain quasistatic modelisation assuming elastic viscoplastic material behaviour pro vides a reasonable tool in order to calculate both local stresses and deformations in a Charp: $\mathrm{V}$-notch specimen to discuss instable fracture in $\mathrm{A} 508 \mathrm{Cl} 3$ bainitic steels at low temperature.

- A new relationship between Charpy V-notch Energy CVN and fracture toughness $K_{I C}$ will be proposed on the basis of key curves giving the cumulative failure probabilities $P_{r}$.

\section{References}

[1] Beremin F.M., Met. Trans. A 14A (1983), 2277-2287.

[2] Benett P.E. and Sinclair G.M., Trans. ASME Series D Jal Basic Engineering 88 (1966), 518-52:.

[3] Ritchie R.O., Server W. L. and Wullaert R.A., Met. Trans. A 1A (1970), 1557-1570.

[4] Pluvinage G. and Marandet B., "Application of local fracture criteria to dynamic fracture toughness" Proceedings of ICF 6, New Delhi (India), 1984, 3151-3158.

[5] Henry M., Marandet B., Mudry F. and Pineau A.,J ${ }^{\text {al }}$ de Méc. théor. et appl. 4 (1985), 741-ibs

[6] Yahya O., Pilvin P. and Piques R., "Polycristalline plasticity and local approach of intergramular brittle fracture in A508 steel" Proceedings of ECF 11, Poitiers (France), 3-6 September 19\%.

[7] Rossoll A., Berdin C., Forget P., Prioul C. and Marini B., "Mechanical aspects of the (harps impact test" Proceedings of ECF 11, Poitiers (France), 3-6 September 1996.

[8] Tahar M., Piques R. and Forget P., " Modelling of the Charpy-V notch test at low temperature for structural steels", Proceedings of ECF 11, Poitiers (France), 3-6 September 1996.

[9] Rossoll A., Tahar M., Berdin C., Piques R,, Forget P., Prioul C. and Marini B., " Local ap. proach of the Charpy test at low temperature", 1st Mechanics of Materials Conference on Local Approach to Fracture, $\mathrm{J}^{\text {al }}$ de Physique IV, Vol 6, (1996), 279-286.

[10] Tahar M. and Piques R., " Résilience et ténacité d'un acier de cuve REP: rôle des veines sombres et des effets d'irradiation", Internal report Ecole des Mines de Paris (France), October 1996. 